\title{
Management of the productivity of information and communications technology (ICT) in the financial services industry
}

\author{
J. W. Gabberty \\ Ivan G. Seidenberg School of Computer Science and Information \\ Systems, Pace University, USA
}

\begin{abstract}
Financial service firms were among the earliest users of information and communications technology (ICT). As introduced in this study, investment in this technology in the banking sector of the industry, initiated in 1970, enabled automation of numerous functions, including loan payment scheduling and automated teller systems. Besides hastening the pace at which functions are performed in the sector, these time-saving improvements reduced the cost of labor, as banking tellers by the thousands were replaced by automated systems. These investments later resulted in fee revenue from customers of the teller systems. The replacement of traditional interest calculation tables, together with spreadsheet programs, resulted in the customization of interest-paying consumer loans. Transaction processing is indicated in this study to have satisfied increasingly larger databases that facilitated the explosion of consumer credit cards and further revenue for the banking sector. The frequent perception that investments in information and communications technology would continue to lower the cost of business while concomitantly and perpetually increasing revenue was the maxim in the sector in 1970-1990. Massive investment by the banking sector in 1990-2000 failed however to support this phenomenon. The failure of the industry to match increasing labor productivity rates was manifest in the sector, as the sector immediately curtailed spending on information and communications technology in 2000-2005. This study evaluates the new relationship of labor productivity and technology, and introduces steps for firms to mitigate the risks of overdependency on the technology. This study will benefit management practitioners and users researching information and communications technology in financial service firms.
\end{abstract}

Keywords: ICT productivity, productivity paradox, United States banking productivity. 


\section{Background}

The tangential issues accompanying information and communications technology (ICT) driven productivity have their origins in a diverse body of research that includes economics, accounting, marketing, management, finance, and information assurance and security; in totality, these diverse topics sources form the basis of current thinking on the topic.

Rarely does an economic indicator garner more attention than the term 'productivity' - especially when used in the context of information and communications technology. Far more meaningful than the terms 'current account', 'unemployment' and 'inflation', productivity is probably the most often used and most misunderstood term used by technology pundits (and the general public) to provide some proximal measure of the impact of technology in a project, process, or enterprise. In simplest terms, a firm is either productive or not - nothing can be simpler - and that is precisely the reason why nearly everyone can understand the broader meaning of the term. But when it comes to measuring both the tangible and intangible aspects of ICT productivity, the risk components associated with ICT, or even the concept of value as applied within the universe of ICT deployment, most managers are hard pressed to fully comprehend the real impact that ICT bears on any firm. Yet implicitly, the terms 'ICT' and 'productivity' seem to go hand in hand; indeed the proliferation of the computer in all aspects of our society has virtually cemented the notion that spending on information and communications technology always results in heightened productivity, though nothing could be farther from reality. The generally accepted perspective upheld universally is that ICT has produced a fundamental change, in particular within the economy of the United States, and has lead to a permanent improvement in growth prospects, as studied by Greenspan [1] and Jorgenson [2]. The final resolution of this perspective however, i.e., the conclusory evidence linking ICT to productivity, has yet to be found.

Economists and academic scholars search in vain for the "killer application", thinking that some elusive program (or suite of programs) will form the core of a new framework for ICT productivity measures to complement those already found in Paul Schreyer's (2001) OECD Manual, Measuring Productivity. But while that search continues, the objective of this paper is to attempt to bring into focus the obfuscated issues surrounding ICT and productivity and their place in the banking sector of the United States.

\section{Relationship of ICT to productivity}

Businesses, especially in the U.S., continue to pump billions of dollars into information and communications technologies. Apparently, these firms perceive ICT as having a value in excess of the aggregate sum of the total monies spent on hardware, software, licensing, programmers, analysts, middleware, training, and all other tangential costs that go into building a firm's ICT arsenal. But how is the total return on these investments measured? Clearly, top executives at 
these companies believe that their investments must be made in lieu of other important assets that the firm could acquire as alternatives to ICT investment(s). These substitute investments might include more staff personnel, additional office space or office locations, higher research and development investments, more pay incentives for key personnel, additional money spent on marketing and sales initiatives, and so on. The use of computers in business, though not entirely new, is still a field shrouded in a sea of complexity, disillusionment, and misunderstanding.

As for calculating the return on ICT investments, at least from the national level, improvement in raising the Gross Domestic Product (GDP) per capita is widely regarded as the best single measure, not only of economic well-being, but also of the aggregate impact of ICT. That measure is simply labor productivity (how many goods and services a given number of employees can produce) multiplied by the proportion of the population that works. Figure 1 illustrates the GDP of the United States on a per capita basis. Also listed is the share of the GDP figure that stems from information technology related industries. Logically, information technology leads to higher productivity levels but the improvements in output capabilities are not reflected by the statistics.

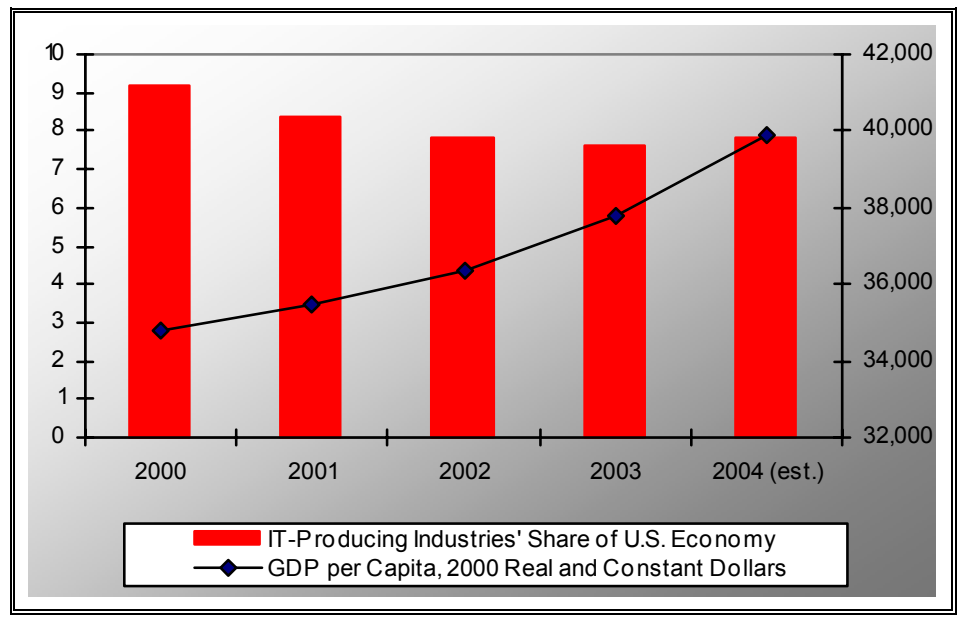

Figure 1: Source: Statistical Abstract of the United States 2006, Table 1113: Gross Domestic Income in Information Technologies (IT) Industries and Table 657: Selected Per Capita Income and Product Measures in Current and Real (2000) Dollars.

Productivity, however, varies enormously among industries and explains many of the differences in GDP on a per capita basis. Thus, to understand what makes countries rich or poor, one must understand what causes productivity to be higher or lower. This understanding is best achieved by evaluating the performance (i.e., output) of employees in individual industries as well as the degree of automation and computerization used in production processes - both manufacturing- and service-related, since a country's productivity is the 
aggregate of total factor productivity for each industry. Such a micro-level approach is extremely costly and time-consuming to perform, yet, if accomplished, would reveal an important fact about productivity: not only does it vary from firm to firm but also varies between industries and also varies widely from country to country.

\subsection{Ascendancy of ICT}

Just over twenty years ago, a study by Warner [3] of Future Computing Inc. posited that 1.4 million personal computers were in use by $10 \%$ to $12 \%$ of office employees in Fortune 2000 firms. The next year, Dell Inc. was founded by Michael Dell. By 2000, that firm would be selling personal computers and peripherals via the Internet in excess of $\$ 50$ million per day, and twenty years after Future Computing's study, Dell's 2004 sales exceeded \$49 billion with an employee base of 55,000. Clearly, ICT had taken hold both in the public and private sector; however the level of complexity associated with calculating both the impact on productivity and costs accompanying ICT also grew at a phenomenal rate.

It is important to note that the lateral costs associated with ICT are not easily calculable and, from this context, relates to costs not easily accounted for, such as administration and upkeep of technology. For example, while a $\$ 1,000$ purchase for a personal computer can be accounted for in terms of costs throughout its useful lifetime (adding peripherals, memory, internet access costs, etc.), assessing the total 'true' cost to create a database on that machine is extremely difficult and varies from computer to computer and from industry to industry. Besides the costs of the database software and licenses, additional (latent) costs can be found in the costs of the administrator's time to have questions answered by existing and planned users, posing a very difficult task for the assessor. Off-line questions asked by the database programmer touch numerous employees as the database expands in complexity and completion. In calculating the costs associated with peripheral employees, whose input is frequently sought throughout construction of a simple database, only then do these true costs become identified and accounted for. Hence, a \$200 database package that has been customized by a database programmer earning $\$ 50,000$ salary (with an additional $\$ 15,000$ in fringe costs), installed on a personal computer with an initial cost of $\$ 1,000$, may bring the total cost of this single installation to a cost in excess of $\$ 250,000$ during its useful lifetime, excluding fixed costs such as rent, electric, HVAC, etc. Obviously, the higher the associated costs of building and maintaining such a straightforward database system drives downward the level of productivity as inputs get consumed to create outputs.

\section{ICT in the financial services industry}

Corporate America and its fascination with and dependence on computers are known internationally. In 2004, for example, the World Economic Forum ranked 
the United States \#1 in its annual Overall Networked Readiness Index, used to provide insight into overall preparedness of a country to participate in and benefit from the networked world. Similar rankings by the World Economic Forum Competitiveness Index also place the United States in the top 3 positions for each of the past 5 years. Much of this competitive performance has been the result of using information and communications technology throughout firms in practically every industry, including financial service firms, such as banks.

Throughout the 1970s, 1980s and early 1990s, banks were among the avid consumers of ICT, enabling them to push decision-making downward in the organization, as discussed by Drucker [4]. Concomitantly this brought about new sources of revenue streams for banks in the form of credit card processing and consumer loans. The rapid transaction processing capabilities of mainframe computers were the backbone of corporate strategic plans for numerous large banks which offered their customers access to cash dispensing machines throughout large metropolitan areas made available 24 hours per day, seven days per week. Large mainframes would also eventually lead to the creation of even newer sources of revenue, in the form of transaction fees for these dispersed automated banking systems.

By the mid-1990s, mergers among American banks increased at faster rates than exhibited previously, and it seemed like technology would continue to be a source of competitive advantage both operationally and strategically ad infinitum. But immediately after the consequent passage of the 1996 Telecommunications Act, making possible the use of the Internet for commercial usage, the banking industry's voracious appetite for information and communications technology had begun to surpass the high rate of return that senior executives had become accustomed to then. In fact, during the late 1990s, productivity trends in retail banking continued to disappoint and began to slide underneath the productivity trajectories exhibited in other industries, as illustrated in Figure 2. While the banking industry's information technology investments accelerated substantially, the sector consistently yielded disappointing labor productivity growth rates, even though these rates were higher than the economy-wide average, declining from $5.5 \%$ during the period 1987 - 1996 to $4.1 \%$ during the period after 1995, as identified by Olazabal [5]. Research into this paradox reveals that the relationship between information technology and labor productivity is more complicated than merely adding the former to lift the latter.

\subsection{Interoperability problems in banking}

Throughout the build-up that continued through the mid-1990s, the ICT investments made by banks were primarily done without taking into consideration the enterprise-level view of the firm, and specifically, how these systems would eventually interoperate. Instead, most of the investments were made in consumer services departments and marketing tools for customer information and support; still other investments were made in back-end applications that automated various corporate functions. This approach was a 


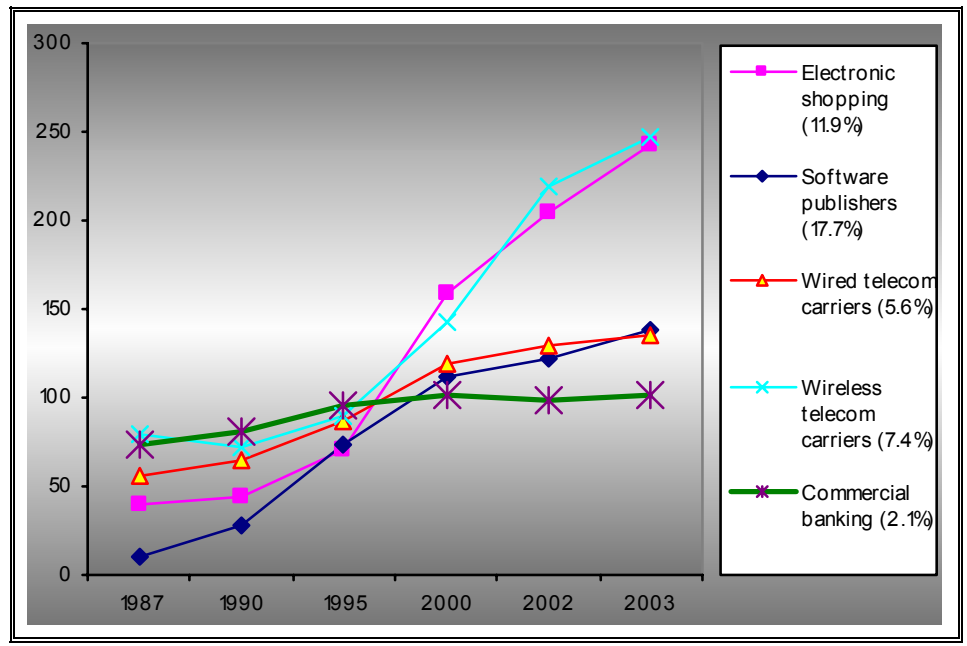

Figure 2: Source: Statistical Abstract of the United States 2006, Table 622: Annual Indexes of Output Per Hour for Selected NAICS Industries.

departure from the traditional, more functionally organized method of implementing change around product lines, such as deposit accounts, loans, and credit cards. As a result, coordination among departments was loose and uncoupled, leading to an erosion of customer information flow throughout the organization.

To mitigate this problem, banks attempted to create a single customer interface, forcing them to integrate databases and downstream ICT systems. Once accomplished, banks adopted newer applications or, more succinctly, customer-relationship-management tools designed to improve customer retention and to facilitate marketing. This massive attempt to interlink the banks' databases required significant investments in personal computers for branch employees and call-center representatives, as well as the integration of complex systems. Also, upgrades in operating systems in the late 1990s caused banks to be burdened with keeping pace with technological change while simultaneously servicing customer needs.

To make matters worse, further effort was put into attracting new customers, primarily with credit card schemes based on elaborate pricing options. At the same time, bank mergers were getting larger. Although the industry consolidated at a steady pace before and after 1995, the size of the banks engaged in mergers grew, largely because of a 1997 regulatory change that lifted the prohibition against interstate bank mergers, which tend to involve larger banks. The average assets of bank merger participants increased from \$700 million (1994-96) to $\$ 1.4$ billion (1997-99). Naturally, the integration of larger systems involved greater complexity.

Lastly, banks were among the horde of firms rushing headstrong into the Internet frenzy of the late 1990s. New, unproven technologies, coupled with third party startup firms, helped banks gain a toehold in the Internet space prior 
to 2000, and this, in essence, not only cost the firms additional dollars but also diverted attention away from the consolidated practices taking place in data centers internationally. As a result, market share among large banks began to slip as smaller, more nimble banks were able to withstand radical changes to their business operations as a result of the technology shifts evidenced in the late 1990s.

\subsection{Net result of poor productivity}

While some of the first attempts brought about by the Internet revolution produced tangible results, such as consumer convenience of conducting transactions on-line and the improved availability of account information available through call centers, automated teller machines, and World Wide Web sites (all of which went under the radar screen of 'captured' productivity improvements, since productivity measures quantity, not quality, of transactions), the costs to integrate disparate systems was enormous. Further, since on-line transactions account for only a small percentage of the banking's revenue stream, these qualitative improvements were not enough to reverse the losses of productivity growth manifest throughout the industry.

It is noteworthy to mention that technology managers are not inherently skilled to the degree that they would include measurement of the myriad intangible aspects for ICT improvements; thus, it become inordinately more difficult to appraise the true value imparted to productivity levels for implementing a costly investment in customer-relationship-management sales tools, for example.

Overinvestment in ICT also resulted from the manner in which banks make their technology purchases. To simplify maintenance of a personal computer for instance, firms often buy either a single or a small number of computer models, meant to satisfy the most demanding users, giving unnecessarily powerful computers to the majority of users. Further, since the more sophisticated end-users also demand newer computers more frequently than do average users, costly department- or even enterprise-wide upgrades become commonplace. Managers at the line level have little knowledge of the larger consequence of their actions and therefore no incentive to oppose this purchasing pattern, causing perpetual and unnecessary ICT investments to be made by firms.

\section{Conclusion}

Despite the generally disappointing results, banks have made enormous investments in information and communications technology. Some of these investments have led to increasing the flow of new customers, lured by the availability to maintain their account information on-line. Other investments were transparent to the end user, such as integrating disparate operating platforms and sophisticated databases. Further, the attention paid to maintaining a secure operating environment has driven upward the cost to the firm of keeping up with competitors. As a result, the level of measured productivity has dropped 
in recent years, as only some of these operational improvements have been captured by the methods employed to measure productivity.

However, the availability of more sophisticated technology obtainable throughout banking translates into a future view that may be characterized as one of significantly improved performance levels, as the investments made over the past ten years reach their full payoff level, and as ICT spending slows. For early adopters of ICT, this is good news; for laggards, the picture is not so rosy. The pressure on banks to offer similar customer service levels, such as the capability for customers to view cashed checks, configuring call centers to automating customer calls using information technology, implementing bill consolidations program for demanding users, etc. places significant burden on a financial services industry searching for additional sources of revenue. As back-office reengineering continues, the dawn of a new era of significantly higher levels of productivity beckons.

\section{References}

[1] Greenspan, A., Challenges for Monetary Policy-Makers, Board of Governors, Federal Reserve System, Washington, October 19, 2000.

[2] Jorgenson, D., Information technology and the G7 economies. World Economics, 4(4), October - December, pp. 139-169, 2003.

[3] Warner, E., Universities promoting micro use in MBA curriculum. Computerworld, 24 September, pp. 40-41, 1984.

[4] Drucker, P., The coming of the new organization. Harvard Business Review, January - February, reprint, 1988.

[5] Olazabal, N. G., Banking: the IT paradox. McKinsey Quarterly, pp. 1,47-51, 2002. 